\title{
ELEMENTOS DA TEORIA CRÍTICA DA DISSONANCIA DE THEODOR W. ADORNO
}

\author{
Daniel Pucciarelli* \\ arelli@gmail.com
}

\begin{abstract}
RESUMO O presente artigo reconstrói e desenvolve os elementos fundamentais da teoria da dissonância elaborada por Theodor W. Adorno em sua filosofia da música. Parte-se de uma breve exposição do tratamento conferido pela musicologia histórica - com toda sua equivocidade autoconsciente e constitutiva - aos conceitos de dissonância e consonância para dele se depreender as linhas fundamentais de um tratamento filosófico da dissonância. Lançando mão dos recursos mobilizados por alguns teóricos da nova música, são reconstruídas, assim, as estações da teoria crítica da dissonância entre desnaturalização, emancipação e liquidação da dissonância. Por fim, defendese a tese de uma interpretação dinâmica do uso e da percepção da dissonância segundo contextos socioestéticos determinados.
\end{abstract}

Palavras-chave Dissonância, Consonância, Nova música, Música moderna, Filosofia da música.

ABSTRACT This article reconstructs and develops the fundamental elements of Theodor W. Adorno's theory of dissonance in his philosophy of music. It begins with a brief explanation on the treatment given by historical musicology, with all its self-conscious and constitutive equivocity, to the concepts of dissonance and consonance, in order to reveal the fundamental lines of a philosophical treatment of dissonance. Using the resources mobilized by some

* Bolsista de pós-doutorado (PNDP-CAPES), Univ. Fed. de Minas Gerais - UFMG. Belo Horizonte/MG - Brasil Artigo submetido em 31/08/17. Aceito em 10/10/17.

KRITERION, Belo Horizonte, no 139, Abr./2018, p. 77-92 
theorists of New Music, the article reconstructs the stations of the critical theory of dissonance among denaturation, emancipation and liquidation of dissonance. In its conclusion, it advances the thesis of a dynamic interpretation of the use and perception of dissonance according to given socio-aesthetic contexts.

Keywords Dissonance, consonance, new music, modern music, philosophy of music.

In fifty years the postman will whistle my tune.

(Arnold Schoenberg)

There will never be a postman that whistles Schoenberg.

(Steve Reich)

\section{Introdução: problema e constelação da dissonância}

"Seguramente não há nada na linguagem do discurso sobre música que seja mais carregado de problemas puramente semânticos do que os termos consonância e dissonância", escreve James Tenney na abertura de seu estudo "A history of 'consonance' and 'dissonance"”. "Uma comparação de algumas definições dessas palavras encontradas em dicionários atuais, manuais de harmonia e livros sobre acústica musical indica que há confusão e dissenso consideráveis quanto a seu significado - se de fato há algum sentido que ainda se possa atribuir a eles" (Tenney, 1998, p. 1). ${ }^{1}$ Como atesta Tenney, a musicologia atual parte do pressuposto de que os termos consonância e dissonância são altamente equívocos. Sua equivocidade parece ser, sobretudo, de natureza semântica, como ele próprio afirma: pergunta-se se e em que medida esses termos referem-se a objetos discerníveis e plenamente individuados do fenômeno sonoro ou se eles são apenas "bolhas de sabão" linguísticas, por assim dizer, sem referente determinado. Nesse caso, a equivocidade dos termos seria tributária, por exemplo, de sua derivação mais ou menos direta 
da prática musical, o que os investiria de utilidade prática, mas não de consistência teórica. Dada a centralidade do que se convencionou chamar de "consonância" e "dissonância" para a compreensão da música ocidental, no mínimo, dos últimos quatrocentos anos e muito particularmente para a música do século XX, no entanto, é certo que a equivocidade dos termos acaba por concernir aspectos mais amplos do fenômeno musical. Parece um lugar-comum descrever a discursividade e energética próprias à música tonal, por exemplo, com o recurso às ideias de tensão e resolução, de direcionalidade, de suspensão e clímax; ideias, enfim, intimamente relacionadas, se não mesmo possibilitadas pelo que se chama ordinariamente de consonância e dissonância. Igualmente comum é a descrição de boa parte da música do século XX em termos de seu aspecto supostamente cacofônico, o que também parece pressupor os mesmos conceitos e seu uso ordinário.

Se transcendermos o registro musicológico e adentramos o estético e particularmente o estético-musical, nos deparamos com o que poderia ser caracterizado como uma constelação da consonância e da dissonância não menos complexa e mesmo problemática. Olivier Baron (2008) procurou sintetizá-la recentemente como se segue: de um lado, a dissonância é historicamente designada como uma espécie de degeneração da consonância ou como algo que exige sua dissolução em consonância, ${ }^{2}$ o que faz com que ela figure como um elemento irracional ou no mínimo menos racional do que a consonância e, enquanto tal, como algo incivilizado, indomado, recalcitrante e mesmo demoníaco. Esteticamente ela é praticamente identificada à categoria do feio. ${ }^{3}$ Simultaneamente, no entanto, a dissonância figura como o símbolo por excelência da modernidade estética e musical, ${ }^{4}$ como algo que deve ser esteticamente libertado e emancipado e que só pode alcançar plenamente esse estatuto na modernidade. Em contraposição à consonância, assim, a dissonância apontaria para a necessidade de liberação do reprimido e do recalcado e para um novo - e mesmo utópico - universo de sentido estético. Note-se assim, na constelação estética da dissonância em particular, a coexistência

2 "Na música, por exemplo, a relação da tônica com a subdominante e dominante não é simplesmente quantitativa; trata-se, ao contrário, de sons essencialmente diferentes que convergem para uma unidade, sem deixar aparecer brutalmente a sua determinidade como contrariedade e contradição gritantes. Dissonâncias [ao contrário] precisam de uma resolução". Hegel (1986, p. 324).

3 "Dissonância é o termo técnico para a recepção, pela arte, do que é chamado de feio tanto pela estética quanto pelo senso comum. O que quer que ela seja, ela deve compor ou poder compor um momento da arte". Adorno (GS7, p. 74).

4 "A dissonância, signo de toda modernidade [...]". Adorno (GS7, p. 29). 
e talvez mesmo a coincidência de um vocabulário negativamente saturado de um ponto de vista "estético-valorativo" ("degeneração", "feio" etc.) e positivamente de um ponto de vista "crítico-normativo" ("emancipação", "liberação" etc.). Como interpretar essa constelação?

A teoria crítica da dissonância desenvolvida por Theodor W. Adorno, cujos principais elementos se pretende reconstruir e problematizar no presente artigo, é uma tentativa de resposta a esses problemas. Não se trata apenas de uma teoria musicológica sobre as diferentes acepções de consonância e dissonância no curso da História, como a que propõe Tenney; trata-se também de uma teoria estética que simultaneamente parta dos problemas colocados pela musicologia moderna e os elabore em um outro nível de metarreflexão filosófica. Partindo das investigações da Tenney, abordarei primeiramente o problema semântico levantado pelo uso dos termos "consonância" e "dissonância" na História da música, particularmente em sua abordagem crítica no século XX. Trata-se de partir do esclarecimento acústico e da relatividade histórica dos termos para refutar a naturalização do fenômeno e, mais radicalmente, propor a sua liquidação (2). O modelo analítico que aponta para a liquidação do que se tradicionalmente entendeu como consonância e dissonância base da teoria crítica da dissonância de Adorno - ganha plausibilidade à luz da assim chamada emancipação da dissonância (3), que corrobora sua dimensão histórica e permite depreender seu significado estético dinamicamente segundo contextos e sistemas de referência musicais e sociais determinados (4).

\section{Consonância e dissonância: breve história dos conceitos}

Segundo o "Handwörterbuch der musikalischen Terminologie" (2006), ${ }^{5}$ os termos consonantia e dissonantia são versões latinas, provavelmente cunhadas por volta do século I a.C., dos termos gregos symphonia e diaphonia. Em seu sentido simples, os substantivos gregos e seus derivados significam respectivamente algo como "soar junto" e "soar separadamente", designando antes de tudo "concordância" ou "discordância" entre dois sons, tal como se depreende deste célebre fragmento de Aristóxenes, da escola peripatética. 
Qualquer que seja o modo, de qualquer nota que se comece, se a melodia se move em progressões contínuas seja para cima ou para baixo, a quarta nota em sequência de qualquer nota deve formar com ela a concordante [symphonon] de quarta, da quinta nota em sequência com ela a concordante da quinta. Qualquer nota que não responda a nenhum desses testes deve ser considerada como não concordante [asymphonoi] em relação a essas notas com as quais ela falha em formar as concordantes supramencionadas. ${ }^{6}$

A definição clássica dos termos latinos, por sua vez, remonta a Boécio ( século V), que caracteriza a consonância como "uma conexão de dois sons de diferentes alturas por meio de proporções numéricas simples"; em sua definição, a dissonância ocupa papel derivado e meramente negativo da definição de consonância. Embora se derive dos termos assim compreendidos uma miríade de sentidos figurados - e, bem entendido, também extramusicais - através dos séculos, a história dos conceitos apresenta certa constância. Via de regra, consonantia e dissonantia designam as seguintes implicações centrais de determinadas classes de intervalos ditos consonantes ou dissonantes: a) o significado constitutivo das proporções numéricas, b) as conotações estéticas a elas associadas, c) a simultaneidade dos sons e d) sua diferenciação. Desde o início, portanto, seja em sua versão grega ou latina, os termos designam opostos qualitativos.

Os problemas dessa nomenclatura clássica se revelam quando se trata de dividir os intervalos ditos consonantes e dissonantes e apresentar os critérios para referi-los a suas respectivas classes. Pois antes de uma constância, o que a musicologia histórica constata é uma profunda variabilidade do que se designou (e percebeu) como intervalos consonantes e dissonantes, o que torna problemáticos os critérios para a sua diferenciação e, no limite, a própria razão de ser dos termos. De antemão, basta se lembrar da percepção sempre ambígua e incerta da quarta desde a Antiguidade até hoje, em permanente oscilação entre consonância e dissonância. ${ }^{7}$ Nesse sentido, Tenney distingue cinco tipos, por vezes ambíguos, de consonância e dissonância desde a Antiguidade

6 Aristoxenus (1974, p. 205).

7 O próprio Tenney reconhece esse estatuto complexo da quarta: "Nas fontes anteriores ao século IX, a quarta foi considerada como a primeira das três consonâncias [...] No século XIII, ela foi uma consonância intermediária, com o mesmo status da quinta perfeita. Agora [século XVII], ou ela é omitida da lista de consonâncias, designada a alguma classe especial entre consonância e dissonância, ou explicitamente listada entre as dissonâncias. A história dessa modificação, no entanto, não foi a de um declínio direto ou gradual em status de consonância à dissonância, e a quarta continuou a ser fonte de desentendimento entre teóricos até os séculos XVIII e XIX. De fato - como diz Richard Crocker -, a 'anomalia da quarta é tão profunda que, de acordo com últimos relatórios, a questão ainda está em aberto'”. Tenney (1999, p. 44). 
até o século XX - a saber: melódico, diafônico, contrapontístico, triádico e timbral -, o que implica igualmente em grande variedade de quais são os complexos sonoros referidos a essa ou aquela classe; o musicólogo insiste, no entanto, que a eles devem corresponder necessariamente correlatos acústicos. Ele resume sua investigação da seguinte maneira:

A pesquisa esboçada nesse livro foi motivada originalmente pelo desejo de clarificar
certas questões que surgiram durante, justamente, uma tal procura de correlatos acústicos
de consonância e dissonância. Essa tentativa chegou a um impasse em certo ponto
com a compreensão de que os vários desacordos teóricos concernentes à consonância
e dissonância não foram apenas desacordos sobre a sua base física (ou outra), mas
desacordos muito mais profundos que têm a ver com a própria natureza do fenômeno
perceptivo designado pelos próprios termos. Obviamente, então, qualquer procura
por "correlatos" (sejam eles físicos, psicológicos, ou outros) - e, consequentemente,
qualquer tentativa de desenvolver uma teoria explicativa de consonância e dissonância
- era condenada ao fracasso quase antes mesmo de começar, uma vez que não havia
consenso sobre o que uma tal teoria precisaria "explicar". Uma de minhas assunções
iniciais foi que - embora muitos dos aspectos importantes da prática harmônica não
seriam acessíveis à pura análise acústica - ao menos alguns deles deveriam ser - e
que não era apenas uma questão de isolar essas formas da pletora de fatos e conceitos
associados com vários períodos na história da prática harmônica que não poderiam
ser tratados acusticamente. Agora, eu estou convencido, no entanto, que correlatos
acústicos podem ser encontrados para cada uma das cinco formas de CDC [conceitos de
dissonância e consonância - CDC] que foram identificadas aqui (Tenney, 1988, p. 100).

Tenney parte do pressuposto de que as diferentes, e muitas vezes contraditórias, concepções do que sejam consonância e dissonância legadas pela tradição nas diferentes épocas correspondem (ou no mínimo devem corresponder) a uma base acústica capaz de legitimá-las. Assim, a teoria de Aristóxenes, que caracteriza apenas os intervalos de quarta e quinta como concordantes e todos os outros como discordantes, poderia ser tão acusticamente fundamentada quanto uma teoria que se baseie, por exemplo, na designação de uma nota dissonante relativa a um centro tonal determinado. Tenney, no entanto, embora não possa oferecer em seu livro uma tal teoria, insiste na sua possibilidade: "Está além do escopo desse livro, no entanto, sequer começar a apresentar uma análise teórica da qual se possa derivar esses correlatos, e essa análise deverá ser apresentada em outro lugar" (Tenney, 1988, p. 100).

É em vista de tais dificuldades e da crescente problematicidade da terminologia no curso da História da música que se principiou, apenas no século $\mathrm{XX}$, a colocar em questão os seus pressupostos. Munidos do progresso técnico e teórico possibilitado pelo desenvolvimento da ciência acústica experimental, teóricos como Stumpf e Schoenberg argumentaram a favor de uma progressiva - mesmo que contraproducente na prática - substituição da terminologia em 
virtude de sua flagrante falsidade. A formulação de Schoenberg na obra "Tratado de harmonia", de 1911, é célebre.

Na sucessão dos harmônicos superiores, que é uma de suas propriedades mais notáveis, surge, depois de alguns sons mais facilmente perceptíveis, um certo número de harmônicos mais débeis. Os primeiros são, sem dúvida, mais familiares ao ouvido, enquanto os últimos, dificilmente audíveis, soam mais inusitados. Com outras palavras: os mais próximos parecem contribuir mais, ou de maneira mais perceptível, ao fenômeno total do som, ao som como eufonia, capaz de arte; ao passo que os mais distantes parecem contribuir menos, ou de forma menos perceptível. Porém, que todos contribuem, mais ou menos, na emanação acústica do som nada se perde, isso é seguro. Também é certo que o mundo sensorial está em relação com o complexo total, também com os harmônicos mais distantes. Se esses sons mais longínquos não podem ser analisados pelo ouvido, são, em troca, percebidos como timbre. Isso significa que o ouvido musical desiste, aqui, das tentativas de uma análise precisa, mas a impressão como um todo é perfeitamente captada. Os harmônicos mais distantes são registrados pelo subconsciente e, quando afloram à consciência, são analisados e relacionados ao complexo sonoro total. Esta relação, digamos outra vez, é a seguinte: os harmônicos mais próximos contribuem mais, os mais distantes, menos. A diferença entre eles é gradual e não substancial. Não são - e a cifra de suas frequências o demonstra - opostos, assim como não são opostos o número dois e o número dez. E as expressões consonância e dissonância, usadas como antítese, são falsas. Tudo depende, tão-somente, da crescente capacidade do ouvido analisador em familiarizar-se com os harmônicos mais distantes, ampliando o conceito de "som eufônico, suscetível de fazer arte", possibilitando, assim, que todos esses fenômenos naturais tenham um lugar no conjunto (Schoenberg, 1999, p. 59f).

A argumentação de Schoenberg foi largamente confirmada por outros estudos musicológicos levados a cabo e publicados ainda à época da aparição de seu "Tratado de harmonia". Esse é o caso, por exemplo, de Carl Stumpf, que realizou, ainda no começo do século XX, experimentos acústicos que também conduziram à necessidade de uma completa reavaliação do fenômeno sonoro e da nomenclatura tradicional. O musicólogo Carl Dahlhaus resenhou o seu artigo "Consonância e dissonância", publicado em 1911, como se segue:

A partir de experimentos com pessoas musicalmente destreinadas, Stumpf conclui sob a premissa de que a consonância entre dois sons será tanto mais marcada quanto mais os sons conjuntos forem considerados como um único som pelas pessoas no experimento - que consonância e dissonância não são duas classes claramente distintas de sons, mas uma sequência de níveis de sonância cuja mais elevada é a oitava e a mais baixa é a sétima maior e o trítono. Entre consonância e dissonância não há diferença específica, mas apenas uma distinção gradual (Dahlhaus, 2002, p. 698).

O modelo argumentativo elaborado em ambos os casos é simples: tomado em seu aspecto físico visualizável, por exemplo, pela cifra de frequências, constata-se que aquilo que a teoria tradicional designa como "consonâncias" corresponde apenas a sons mais próximos, e "dissonâncias" a sons mais distantes 
da nota fundamental; por sua vez, a distância da nota fundamental determina apenas quantitativamente a sua audibilidade e, consequentemente, o seu grau de influência sobre aquilo que Schoenberg chama de "fenômeno total do som" (Gesamterscheinung des Tones), composto, bem entendido, tanto pelos harmônicos mais próximos quanto mais distantes. Assim, em que sentido se pode dizer que há "concordância" ou "discordância" de sons mais próximos ou mais distantes do fundamental, se a sua diferenciação física é apenas quantitativa? Em outros termos, em que sentido se pode dizer que a combinação de harmônicos mais distantes está em oposição qualitativa à combinação de harmônicos mais próximos, como a terminologia leva a concluir? Nesse sentido, em sua análise dos conceitos de dissonância e consonância, Schoenberg e Stumpf substituem a relação de oposição qualitativa entre os dois termos por uma gradação de níveis de sonância, o que dá lugar a uma espécie de pedagogia musical dos níveis de sonância.

A nova análise da distinção entre consonância e dissonância introduzida aqui conduz, em certo sentido, à sua liquidação: dado que a diferenciação entre consonância e dissonância corresponde apenas aos hábitos auditivos e à perícia técnica do ouvido musical, então se deve reconhecer que os complexos sonoros por elas formados não configuram opostos naturais, mas instâncias de sonância graduais em um contexto sonoro determinado. Não se pode, em outros termos, tomar dois objetos musicais distintos caracterizados como "consonantes" e "dissonantes" e interpretá-los em uma oposição qualitativa e essencial, o que é o mesmo que dizer que, a rigor, não há consonâncias e dissonâncias em música. Novamente, a sua relação com o "fenômeno total do som" é qualitativamente igual, apenas quantitativamente diversa.

Pode-se dizer que o modelo teórico de Schoenberg e Stumpf está na base da teoria crítica da dissonância elaborada por Adorno. Também ele afirma inequivocamente que "o processo histórico liquidou a oposição entre consonância e dissonância” (Adorno, GS15, p. 178) e que, com a nova música, "há apenas dissonância e, com isso, nenhuma mais" (Adorno, GS18, p. 74). Trata-se, por assim dizer, de um dos fundamentos da teoria crítica da dissonância, na medida em que ela permite, em primeiro lugar, efetuar a desnaturalização do que se entende tradicionalmente por complexos sonoros consonantes e dissonantes como opostos qualitativos e, com ela, das conotações figurativas e estéticas a elas associadas. Desnaturalizados, pode-se interpretar esses complexos sonoros segundo sistemas de referências, contextos e constelações musicais e históricas mais amplas e mutáveis. Em segundo lugar, porque ela permite que se estabeleçam critérios para se avaliar criticamente os hábitos e padrões de um determinado ouvido musical e, conseguintemente, elaborar uma pedagogia musical dos níveis de sonância que visariam a compreensão de 
relações sonoras mais complexas do que o binarismo consonância-dissonância. Ambos os elementos estão paradigmaticamente entrelaçados na problemática da emancipação da dissonância. Antes de desenvolvê-la, podemos resumir, para sua melhor visibilidade, a argumentação desenvolvida até aqui em poucas teses simples.

1. Consonância e dissonância não correspondem, em realidade, a uma oposição qualitativa, como a terminologia dá a entender, mas apenas a maiores ou menores níveis de sonância que se diferenciam apenas quantitativamente da nota fundamental.

2. O fato de que determinados níveis de sonância recebam o caráter de "consonâncias" ou "dissonâncias" só é possível no interior de um sistema sonoro artificial, que cria uma sintaxe, uma energética e uma estética musicais e, com isso, hierarquiza artificialmente os diferentes níveis de sonância segundo as coordenadas desse sistema sonoro. Como se sabe, o sistema sonoro dominante no Ocidente desde a modernidade é a tonalidade. A constelação da dissonância nos últimos quatro séculos deve ser lida a partir desse sistema sonoro (e de suas contradições, esgotamentos e insuficiências internas).

3. Outros sistemas sonoros que não hierarquizem dessa maneira os níveis de sonância e, com isso, não se baseiem nessa sintaxe e energética musicais são inteiramente possíveis; nesses sistemas alternativos, os mais diversos níveis de sonância podem permanecer qualitativamente iguais, de forma que deles não resultem (a percepção de) "consonâncias" ou "dissonâncias" (como é o caso da técnica dodecafônica e de seus derivados).O desenvolvimento interno do sistema tonal no Ocidente conduziu - não por último, por meio da emancipação da dissonância - à necessidade de se formular semelhantes sistemas sonoros.

\section{Emancipação da dissonância}

A emancipação da dissonância é uma narrativa sobre o desenvolvimento musical no ocidente mobilizada, sobretudo, pelos adeptos da nova música em geral. Trata-se de um processo levado a cabo através de toda a história da música, mas efetivamente realizado apenas com a modernidade musical. Partindo-se do diagnóstico geral supramencionado de que os intervalos e as conjunções sonoras designados como "consonantes" e "dissonantes" sofreram várias modificações no curso da História, pode-se afirmar com alto grau de confiabilidade que sempre menos intervalos e complexos sonoros desempenharam a função de e foram percebidos como rigorosamente dissonantes em contextos análogos. Em outras palavras, e apesar das dificuldades colocadas em toda argumentação teleológica, 
a História da música ocidental parece poder ser interpretada como um processo, justamente, que conduziu à progressiva autonomização de complexos sonoros tidos como dissonantes. O musicólogo Jam Samson interpreta esse processo como a perda de funcionalidade estético-musical da dissonância no interior de um dado contexto.

\begin{abstract}
À medida em que o ouvido se aclimatiza a uma sonoridade no interior de um contexto particular, a sonoridade irá gradualmente tornar-se emancipada daquele contexto e procurar um novo. A emancipação das dissonâncias dominantes seguiu esse padrão, com a sétima dominante ocupando o status, no século XVI, de uma nota contrapontística para uma nota harmônica quase contrapontística no começo do século XIX. Ao final do século XIX, as dissonâncias dominantes, maiores em número, haviam adquirido status harmônico, com a resolução atrasada ou completamente omitida. A maior autonomia da dissonância dominante contribuiu significativamente para o enfraquecimento da função tonal tradicional no interior de um contexto puramente diatônico (Samson, 1977, p. 146).
\end{abstract}

Também Adorno mobiliza a narrativa da emancipação da dissonância como objeto de reflexão sobre seu estatuto musicológico e estético. Seu tratamento do fenômeno é, no entanto, mais abrangente. Trata-se de compreender o paulatino processo de emancipação da dissonância sob uma dupla tendência: de um lado, em concordância com a hipótese de Samson, pode-se interpretar a emancipação da dissonância do ponto de vista de sua dimensão funcional ou, nas palavras de Adorno, construtiva e "puramente musical" (GS18, p. 73) para a constituição do idioma musical. Trata-se, aqui, da progressiva eleição da dissonância como princípio estruturador da harmonia. De outro lado, a emancipação da dissonância seguiu também um princípio expressivo de veiculação subjetiva de conteúdos negativos, recalcados e "incivilizados". Ainda que ambas as tendências sejam essencialmente complementares e tenham se consumado na passagem do romantismo para a modernidade musical, elas não necessariamente correram paralelamente ou correlativamente no decorrer da História da música. Ademais, vê-se que Adorno procura congregar em um mesmo tratamento teórico todos os elementos da constelação da dissonância supramencionada.

No que concerne à tendência construtiva-estrutural da emancipação da dissonância, a narrativa elaborada por Adorno é conhecida. Segundo essa narrativa, a constituição plena do idioma tonal teria sido realizada apenas com o Classicismo musical, após, portanto, a consolidação da tecnologia intra e extraestética necessária para a sua instauração, como, paradigmaticamente, o temperamento e os correlativos monumentos à racionalização musical que o acompanharam (como é o caso de "O 
cravo bem-temperado"). Assim, apenas a partir do Classicismo, e muito particularmente no período "heroico" de Beethoven, foi possível aliar a organização total da forma musical unicamente a partir de estruturas motívico-temáticas micrológicas (baseadas, por sua vez, apenas nas regras elementares da tonalidade) à afirmação da liberdade compositiva do sujeito musical; aqui, nesse período simultaneamente profícuo e frágil, o uso da dissonância fora inteiramente subordinado às regras da tonalidade, que oferecia uma lógica discursiva coesa para a energética musical. ${ }^{8}$ Já a partir do dito período tardio de Beethoven até o movimento romântico, há uma progressiva dissociação de construção formal e liberdade compositiva: a dissonância passa a se autonomizar dos contextos funcionais da forma integral, o que implica em uma perversão de seus sentidos idiomáticos "originais". Ela passa a provocar "cesuras no idioma" (Adorno, GS16, p. 655). Aqui, Adorno se refere particularmente à utilização reiterada e autonomizante de acordes de seis e sete sons "dissonantes" em Wagner e Strauss.

Mas já em meados do século XIX, Wagner (Walküre, $2^{\circ}$ Ato, um compasso antes da grande entrada de Wotan, "O heilige Schmach") chega à formação de um acorde que contém seis sons diferentes (C-F-Ab-Db-Cb-Ebb), no qual, por meio de sua posição separada, os quatro sons mais dissonantes do intervalo de segunda menor soam simultaneamente; um acorde, portanto, do tipo que desempenhou um papel importante particularmente em uma fase determinada da atonalidade livre. Obviamente, essas dissonâncias podem ser interpretadas no sentido da harmonia tradicional como sons "estranhos à harmonia" (combinação de tom pedal e formação de apogiatura); como elas vão para o primeiro plano graças à uma particular expressividade e ênfase, no entanto, elas assumem o caráter de uma certa autonomização e passam a ser compreendidos como "acordes" de tipo próprio, independentemente de sua gênese no esquema harmônico. Essa tendência à autonomização da dissonância cresce tanto no último Wagner que alguns complexos sonoros como acordes do tipo (E-C\#-G-B-F) no "Crepúsculo dos deuses" (no Rheintöchterdrohung) e no "Parsifal" (motivo de Kundry) atuam como acordes condutores (Leitakkorde). Em toda a posteridade de Wagner, o campo da dissonância foi cada vez mais expandido. Um certo ponto de viragem é o acorde de reconhecimento na cena de Orestes, da "Elektra" de Richard Strauss, que contém sete sons diferentes. Ele não é mais expressão do desespero, mas serve para refletir as sensações contraditórias e tumultuosas do momento estático; um acorde igualmente articulado e móvel em si mesmo. A partir de então, a dissonância se torna capaz de congregar em si todas as possibilidades da expressão; caducando a

8 "Afinal de contas, o que é a tonalidade? Uma tentativa de submeter a música a uma lógica discursiva, a uma espécie de conceitualidade genérica. $E$ isso de modo tal que as relações entre acordes idênticos deva significar sempre o mesmo para ela. Trata-se de uma lógica das expressões ocasionais. Toda a história da música mais recente é a tentativa de 'preencher' essa lógica musical extensiva: Beethoven [foi] aquele, no entanto, que desenvolveu seu próprio conteúdo a partir dela mesma, todo sentido musical a partir da tonalidade" (Adorno, 2004, S. 83). 
oposição consonância $=$ prazer e dissonância $=$ dor, o conceito de consonância perde a sua validade e, com isso, em sua universalidade, também o próprio conceito de dissonância (Adorno, GS18, p. 73f).

Em outras palavras, trata-se aqui do uso paulatino da dissonância como material de ordenação harmônica, que conduz diretamente à dissolução da tonalidade no jovem Schoenberg - ele próprio se valendo do expediente da autonomização da dissonância em acordes complexos, como é o caso do uso do famoso acorde de nona invertida da Noite transfigurada. Se seguirmos a interpretação de Adorno, vê-se que esse desenvolvimento é levado a cabo primariamente em virtude das necessidades compositórias internas de uma tradição bem marcada e coesa da música germânica. O filósofo chama a atenção para outras tradições, no entanto, cujos esforços técnicos também podem ser lidos como conduzindo à emancipação da dissonância em sentido técnico comparável: esse é o caso, por exemplo, do uso impressionista da harmonia em Ravel; do uso da dissonância como figuração da dor física no "Sacre" de Stravinsky (em oposição, portanto, ao seu uso "psicologizante" no romantismo); da constituição, em Bartók, da coma impressionista em um intervalo de segunda menor etc. (Adorno, GS18, p. 75). Todos seriam esforços, em uma palavra, de liberar a dissonância de seu uso original no interior do esquema tonal, transformando-a em material compositivo com outras funções.

Essa tendência construtiva-estrutural foi acompanhada, como dito, por uma tendência expressiva de emancipação da dissonância. Em certos momentos, Adorno parece inclusive conferir primazia a essa tendência.

Talvez a emancipação da dissonância não seja primeiramente, como ensina a história da música oficial, o resultado do desenvolvimento do romantismo tardio pós-wagneriano, mas o anseio por ela tenha acompanhado subterraneamente toda a música burguesa desde Gesualdo e Bach, comparável ao papel desempenhado pelo conceito de inconsciente na história da ratio burguesa. Não se trata aqui de mera analogia, pois a dissonância foi desde o começo portadora de tudo aquilo que sucumbiu ao tabu da ordem. Ela responde pela excitação pulsional censurada. Ela contém, como tensão, tanto um momento libidinoso como a queixa pela recusa (Versagung). A fúria com que todos reagem à dissonância poderia ser explicada assim (Adorno, GS12, p. 196).

E ainda:

Se é verdade que a dissonância sobressai decididamente na música atual, para então liquidar a consonância e com isso o próprio conceito de dissonância, então poder-se-ia mostrar que desde muitos séculos os compositores foram atraídos pela dissonância no sentido da possibilidade de, como subjetividade reprimida e sofrimento sob a não-liberdade, pronunciar a verdade sobre a catástrofe imperante. Os instantes mais elevados foram aqueles nos quais o momento dissonante se afirmava e simultaneamente 
se dissolvia no equilíbrio do todo, historiografia interior da negatividade assim como imagem antecipatória da reconciliação (Adorno, GS10.1, p. 295).

A chave da compreensão da tendência expressiva da emancipação da dissonância é que a ela associaram-se progressivamente conteúdos subjetivos que, em sua irrupção, apresentam simultaneamente uma verdade sobre processos não apenas estético-musicais, mas civilizatórios como um todo. Assim, ela pode ser interpretada do ponto de vista filosófico (como o negativo), civilizatório (como aquilo que "sucumbiu ao tabu da ordem"), somático (como sofrimento), psicanalítico (como "excitação pulsional censurada"), etc. A premissa desse argumento, em uma radicalização de Max Weber, ${ }^{9}$ é que a dissonância estaria em correlação imanente a esses conteúdos porque à constituição do sistema tonal subjazem os mesmos processos de racionalização presentes no desenvolvimento societal do ocidente nos últimos séculos. Haveria, em outros termos, o que poderíamos chamar de uma "isomorfia mediada" 10 entre eles. A necessidade de expressão subjetiva explicaria, assim, a razão pela qual um sistema sonoro como o tonal não pôde estacionar-se, por exemplo, no período heroico de Beethoven, momento de sua máxima consistência e acabamento formal; seu fechamento carregava algo de ilusório e mesmo ideológico, desmentido, por sua vez, pelo desenvolvimento posterior da música romântica até a música moderna. Daqui depreende-se a relação entre dissonância e sociedade, com a qual culmina a teoria crítica da dissonância de Adorno.

\section{Conclusão: dissonância e sociedade}

As estações da teoria crítica da dissonância percorridas até aqui nos conduziram da desnaturalização da compreensão tradicional de consonância e dissonância como opostos qualitativos até a progressiva emancipação e a

9 Weber desenvolveu sua célebre tese em Weber (1972).

10 Como se sabe, trata-se aqui de um desdobramento da célebre - e controversa - tese de Adorno, presente em Dialética negativa, de que haveria uma "relação de protoparentesco" entre o princípio de identidade que rege o pensamento e o princípio da troca da sociedade capitalista (cf. Adorno, GS6, p. 149). Essa relação possibilitaria desenvolver de maneira espelhada a crítica da sociedade capitalista avançada, cujo procedimento é de uma radicalização do princípio de troca, e os sistemas filosóficos da modernidade (particularmente o hegeliano), baseados no princípio de identidade. Poder-se-ia, assim, realizar o desiderato da teoria crítica de efetuar crítica do conhecimento e crítica social a uma só vez. Como se lê no seu manuscrito inacabado sobre Beethoven (2004), Adorno parecia no mínimo tatear no sentido dessa mesma relação quanto aos princípios elementares de constituição do sistema tonal, de modo que haveria uma correlação imanente entre sociedade capitalista, sistema filosófico e sistema tonal. Procurei desenvolver este ponto no que concerne à relação entre Beethoven e Hegel em Pucciarelli (2014). 
consequente dissolução da dissonância. Como vimos, a hipótese defendida por Adorno converge no sentido de se afirmar que a emancipação da dissonância obedeceu a uma dupla tendência: a construtivo-estrutural e a expressiva. Embora tenha uma orientação primariamente imanente - ou, se quisermos, internalista - de interpretação do fenômeno a partir da configuração e da constituição do idioma musical, a hipótese de Adorno tem como premissa uma correlação entre ela e a sociedade. Segundo essa premissa, à música e à sociedade subjazem mediatamente processos análogos de racionalização, o que faz com que a constituição do idioma musical responda e reaja, em seu próprio meio, aos problemas e impasses da sociedade. Sem dúvida, essa tese corresponde a uma das ideias mais antigas de Adorno para a interpretação materialista de objetos musicais (e estéticos como um todo); ela já se encontra formulada claramente em um texto de 1932 intitulado "Sobre a situação social da música": "Onde quer que a música hoje ressoe, ela traça nas suas linhas mais determinadas as contradições e rupturas que atravessam a sociedade atual e é simultaneamente, em virtude da mesma ruptura, separada da sociedade que produz a ela e a essas rupturas" (Adorno, GS8, p. 729).

Bem entendido, essa tese será tanto mais verificável quanto mais um único princípio de organização social - e, com ele, de constituição e dominação técnica de um determinado idioma musical - se universalizar, como, para Adorno, é o que ocorre no capitalismo avançado com a virtual extinção de espaços não capitalistas e de idiomas musicais pré-tonais. Isso não impede, no entanto, que se analise o desenvolvimento do material musical e, correlativamente, a função da dissonância segundo contextos e conjunturas sociais específicas. É o próprio Adorno que o faz em uma interessante nota de rodapé de "Filosofia da nova música".

Onde a tendência de desenvolvimento da música ocidental não se impôs puramente, como em algumas regiões agrárias do sul da Europa, foi possível utilizar até muito recentemente material tonal sem vergonha. Pense-se na arte territorial, mas monumental em sua consistência de Janacek, e também em muito de Bartók, que certamente, em toda inclinação folclórica, pertencia simultaneamente à mais avançada música artística europeia. A legitimação dessa música periférica reside em todo caso no fato de que ela forma um cânone técnico consistente e seletivo (Adorno, GS12, p. 126, nota 3).

Adorno considera aqui, em uma palavra, a relatividade social e mesmo contextual do idioma musical e do padrão técnico que ele teria alcançado. $\mathrm{O}$ fato de que tenha sido possível utilizar "sem vergonha" material tonal em certos contextos socioestéticos "até muito recentemente" - o texto data de 1940-1 parece indicar que o filósofo considerava que a completa saturação do idioma teria se dado justamente nesse período, incluídos aí os contextos musicais 
"periféricos" e portanto inicialmente retardatários em relação ao desenvolvimento musical (e socioeconômico) dos países centrais do capitalismo. Sobretudo a partir do pós-guerra, portanto, Adorno tenderá a considerar o idioma tonal e o uso crítico da dissonância como incontornavelmente superado na totalidade do mundo capitalista. Como se sabe, é objeto de controvérsia especializada, desde pelo menos a importante interpretação crítica de Peter Bürger (1983) da estética adorniana, se e em que medida se pode efetivamente falar em um único padrão técnico do material a cada momento histórico e contexto sociocultural; Bürger defende a tese da disponibilidade de uma pluralidade de materiais e de padrões técnicos - inclusive tradicionais - segundo contextos socioestéticos específicos e particularmente nos países ditos centrais, onde há maior acessibilidade aos diferentes recursos estéticos - mesmo sob condições do capitalismo avançado. Embora o texto da "Filosofia da nova música" deixe transparecer um certo "progressismo técnico", no que concerne à eleição do material pós-tonal e assim justifique a crítica de Bürger, os textos musicais de Adorno redigidos no pós-guerra até "Vers une musique informelle", de 1961, demonstram evidente hesitação sobre o caminho de radicalização da música serial levada a cabo no interior da chamada Escola de Darmstadt.

Em vista dessa dimensão contextual e mesmo relativa da teoria crítica da dissonância de Adorno, por fim, pode-se dizer que ela é um meio de análise estética que opera em diferentes níveis: ao mesmo tempo em que realiza a desnaturalização de dissonância e consonância como opostos qualitativos estanques e de suas correlativas noções estéticas, ela também é capaz de medir o uso da dissonância, por assim dizer, de maneira sintomatológica e contextual. Em certo sentido, a dissonância é um meio a partir do qual ela tanto mede o padrão técnico de construtos musicais concretos que ainda se inscrevem no idioma tonal quanto permite interrogar, inversamente, o contexto socioestético - inclusive do ponto de vista, por exemplo, da pedagogia musical - no interior do qual eles se situam.

\section{Referências}

ADORNO, T. „Gesammelte Schriften“. Herausgegeben von Rolf Tiedemann. Vários volumes. Suhrkamp, 1986. (Citado com GS seguido do número do volume e da página). ADORNO, T. "Beethoven: Philosophie der Musik". In: Nachgelassene Schriften, Band 1, Suhrkamp, 2004.

ARISTOXENUS. "The Harmonics". H. S. Macran (ed.). Hildesheim: Georg Olms, 1974. BARON, O. "Dissonanz als ästhetische Kategorie". Wilhelm Fink, 2008. BÜRGER, P. "Das Altern der Moderne”. In: FRIEDEBURG/HABERMAS (ed.). Adorno-Konferenz 1983. Suhrkamp, 1983. 
DAHLHAUS, C. Gesammelte Schriften, Band 4, Laaber, 2002.

EGGEBRECHT et al. (ed.). "Handwörterbuch der musikalischen Terminologie". Steiner, 2006.

HEGEL, G. W. F. "Vorlesungen über die Ästhetik". In: Werke, Band 13, Suhrkamp, 1986. PUCCIARELLI, D. "Só há Beethoven e Hegel? Breve reflexão sobre uma frase de Adorno". Artefilosofia, 16, 2014.

SAMSON, J. "Music in Transition: A Study of Tonal Expansion and Atonality, 19001920". New York, 1977.

SCHOENBERG, A. "Harmonia”. Tradução de M. Maluf. UNESP, 1999.

TENNEY, J. "A history of 'consonance' and 'dissonance"”. Excelsior Music Publishing Co., 1988.

WEBER, M."Die rationalen und soziologischen Grundlagen der Musik". In: Schriften zur Musiksoziologie. Tübingen, 1972. 